\title{
Effect of Two Blanching Methods on the Nutritional Values of Tomatoes and Pumpkin Leaves
}

\author{
${ }^{*}$ SUNMONU, MO; ${ }^{1}$ ODEWOLE, MM; ${ }^{2}$ AJALA, EO; ${ }^{3}$ SANI, ROA; ${ }^{4}$ OGUNBIYI, AO \\ ${ }^{* 1,3}$ Department of Food Engineering, University of Ilorin, Ilorin, Kwara State, Nigeria \\ ${ }^{2}$ Department of Chemical Engineering, University of Ilorin, Ilorin, Kwara State, Nigeria \\ ${ }^{4}$ Department of Agricultural and Biosystems Engineering, University of Ilorin, Ilorin, Kwara State, Nigeria
}

*Corresponding Author Email: sholams2000@yahoo.co.uk; other authors email: odewole2005@yahoo.com; olawaleola01@yahool.com; rafatabdulraheem@yahoo.com; aishatomolola@ymail.com

\begin{abstract}
Various blanching methods were applied to tomatoes and pumpkin leaves (Telfairia occidentalis) to investigate the effect of the different blanching method on some of its nutritional content. The effects of steam and water blanching as a pretreatment on raw tomatoes and pumpkin leaves (control) were investigated in this study using standard methods. For tomatoes, the \%nitrogen, potassium, vitamin A, C and E) $\mathrm{mg} / 100 \mathrm{~g}$ for raw were; $0.48,68.82 \mathrm{mg} / 100 \mathrm{~g}$, $0.88 \mathrm{mg} / 100 \mathrm{~g}, 38.82 \mathrm{mg} / 100 \mathrm{~g}, 0.78 \mathrm{mg} / 100 \mathrm{~g}$ respectively. $0.45,69.68 \mathrm{mg} / 100 \mathrm{~g}, 0.58 \mathrm{mg} / 100 \mathrm{~g}, 32.43 \mathrm{mg} / 100 \mathrm{~g}$ and $0.55 \mathrm{mg} / 100 \mathrm{~g}$ for water blanched respectively and $0.42,69.14 \mathrm{mg} / 100 \mathrm{~g}, 0.47 \mathrm{mg} / 100 \mathrm{~g}, 29.66 \mathrm{mg} / 100 \mathrm{~g}, 0.42 \mathrm{mg} / 100 \mathrm{~g}$ respectively for steam blanching. * For pumpkin leaves, the \%nitrogen, potassium, vitamin A, C and E) $\mathrm{mg} / 100 \mathrm{~g}$ for raw were; $0.98,46.82 \mathrm{mg} / 100 \mathrm{~g}, 4.63 \mathrm{mg} / 100 \mathrm{~g}, 60.41 \mathrm{mg} / 100 \mathrm{~g}, 0.89 \mathrm{mg} / 100 \mathrm{~g}$ respectively. $0.95,46.73 \mathrm{mg} / 100 \mathrm{~g}, 2.38 \mathrm{mg} / 100 \mathrm{~g}$, $41.08 \mathrm{mg} / 100 \mathrm{~g}$ and $0.59 \mathrm{mg} / 100 \mathrm{~g}$ for water blanched respectively and $0.94,46.10 \mathrm{mg} / 100 \mathrm{~g}, 1.20 \mathrm{mg} / 100 \mathrm{~g}, 32.16 \mathrm{mg} / 100 \mathrm{~g}$, $0.52 \mathrm{mg} / 100 \mathrm{~g}$ respectively for steam blanching. The results indicate that water and steam blanching significantly reduce the nutritional content. The values of the nutrient were higher in water blanching compared to steam blanching.
\end{abstract}

DOI: https://dx.doi.org/10.4314/jasem.v25i2.7

Copyright: Copyright $(92021$ Sunmonu et al. This is an open access article distributed under the Creative Commons Attribution License (CCL), which permits unrestricted use, distribution, and reproduction in any medium, provided the original work is properly cited.

Dates: Received: 12 December 2020; Revised: 26 January 2021; Accepted: 12 February 2021

Keywords: Fruits, vegetable, steam, water, blanching

Blanching is a cooking process in which food substance, usually a vegetable or fruit is scalded in boiling water, removed after a brief, timed interval, and finally plunged into iced water or placed under cold running water to halt the cooking process (Reyes et al., 2004). Blanching is used to destroy enzymatic activity in vegetable and some fruit prior to other processing like freezing or dehydration or canning or thermal processing. It is a pretreatment applied to food before the main processing steps by mild heat for a specific time followed by rapid cooling or passing immediately to the next processing stage. Other effect of blanching on fruits and vegetable include; expelling of air and gases in the product, reduction in the product volume (BAT, 2005). The factors that influence the blanching time are; (1) the type of fruit or vegetable (2) the size of the pieces of food (3) the blanching temperature and (4) the method of heating (Fellows, 2006). In steam blanchers, a product is transported by a chain or belt conveyor through a chamber where "food-grade" steam at approximately $100^{\circ} \mathrm{C}$ is directly injected. Usually, temperature in the headspace is measured and the flow rate of steam is controlled. Steam blanching is usually used for cut and small products, and requires less time than water blanching because the heat transfer coefficient of condensing steam is greater than that of hot water (refer to the articles "Convection Heat Transfer in Foods" and "Convective Heat Transfer Coefficients"). (Reyes et al., 2004). Water blanching is performed in hot water at temperatures ranging typically from $70 \mathrm{C}$ to $100 \mathrm{C}$. However, low temperature long-time (LTLT) blanching and combinations of LTLT with high-temperature shorttime (HTST) blanching have also been studied. Water blanching usually results in a more uniform treatment, allowing processing at lower temperatures. There are water blanchers that use a screw or a chain conveyor to transport the product inside the tank, where hot water is added. Others use a rotary drum to immerse and convey the product. Water is usually heated indirectly with steam in a heat exchanger; therefore, steam quality does not need to be "food-grade." Water blanching requires longer processing times, results in increased leaching of minerals and nutrients such as vitamins, and produces effluents with large biological oxygen demand (BOD). The objective of this paper is to investigate the effects of steam and 
water blanching on the nutritional compositions of tomato and pumpkin leaves.

\section{MATERIALS AND METHODS}

Sample preparation: Fresh tomatoes were purchased from mandate market Ilorin Kwara State, Nigeria. The tomatoes and pumpkin leaves were rinsed with warm water and then cut into average sizes of $5 \mathrm{~mm}$ and $10 \mathrm{~mm}$ thickness for easy penetration of steam. The already cut tomatoes and pumpkin leaves were arranged on the blanching net. Water was filled into the blanching pot to a level below the blanching net and the blanching net containing the cut tomatoes were inserted and then tightly covered with its lid.

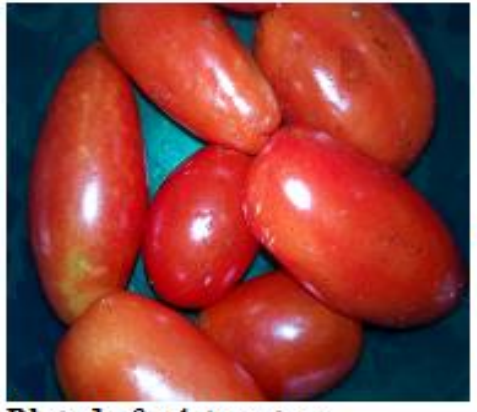

Plate 1: fresh tomatoes

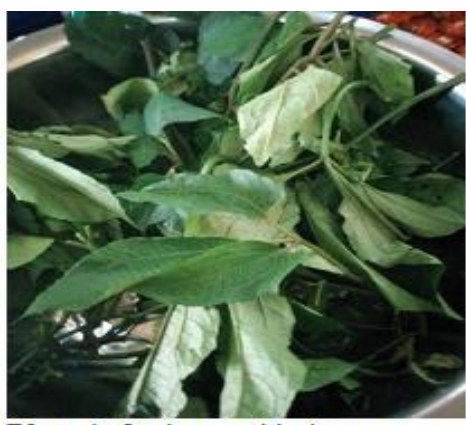

Plate 4: fresh pumpkin leaves

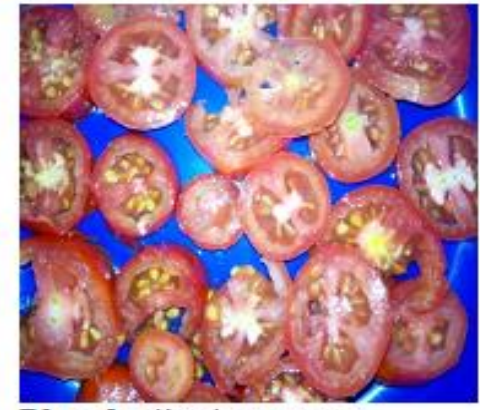

Plate 2: sliced tomatoes

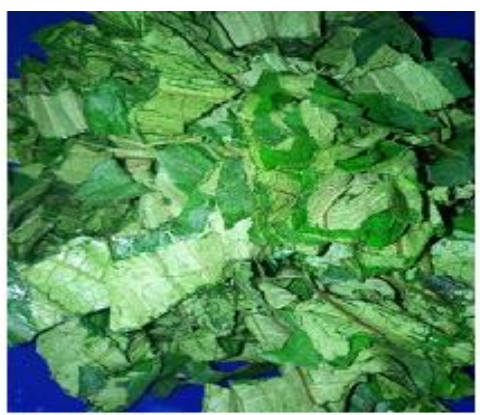

Plate 5: freshly cut pumpkin

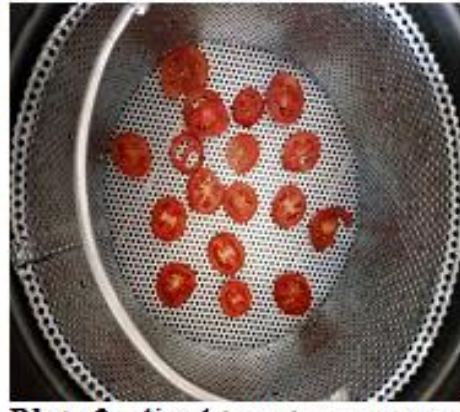

Plate 3: sliced tomatoes arranged in the blanching net

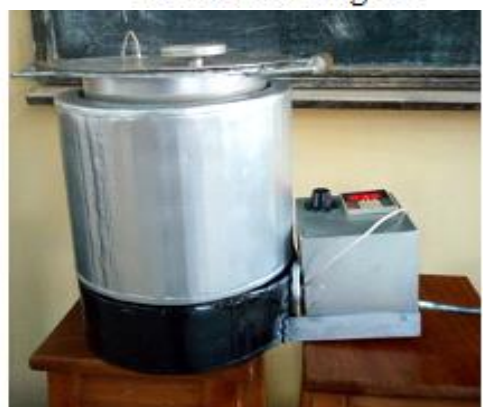

Plate 6: Pictorial View of Fruit and leaves Vegetable B lancher

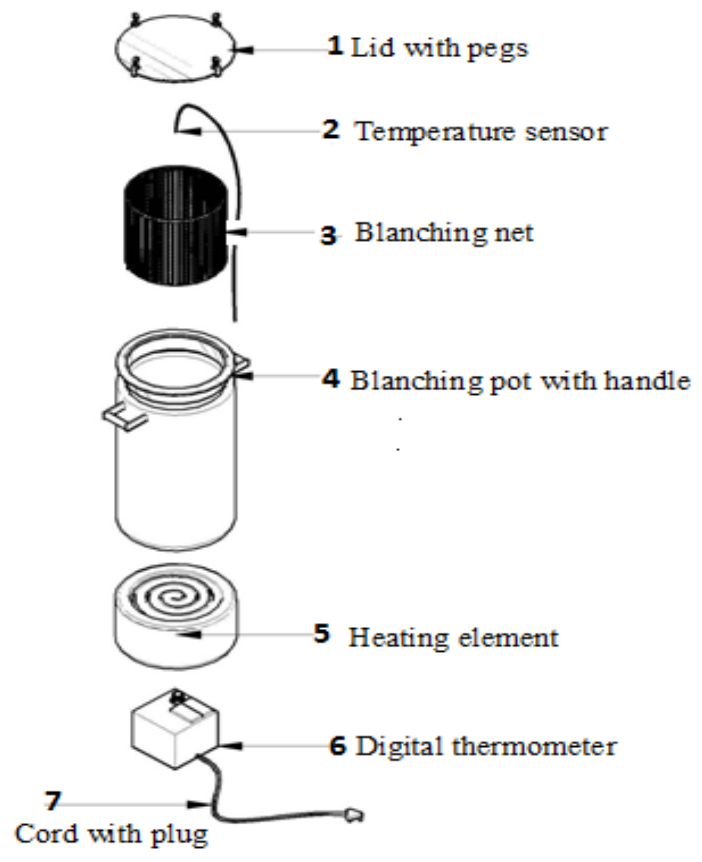

Fig 3a. Exploded View of the Fruit and Vegetable Blancher (Electric Source)

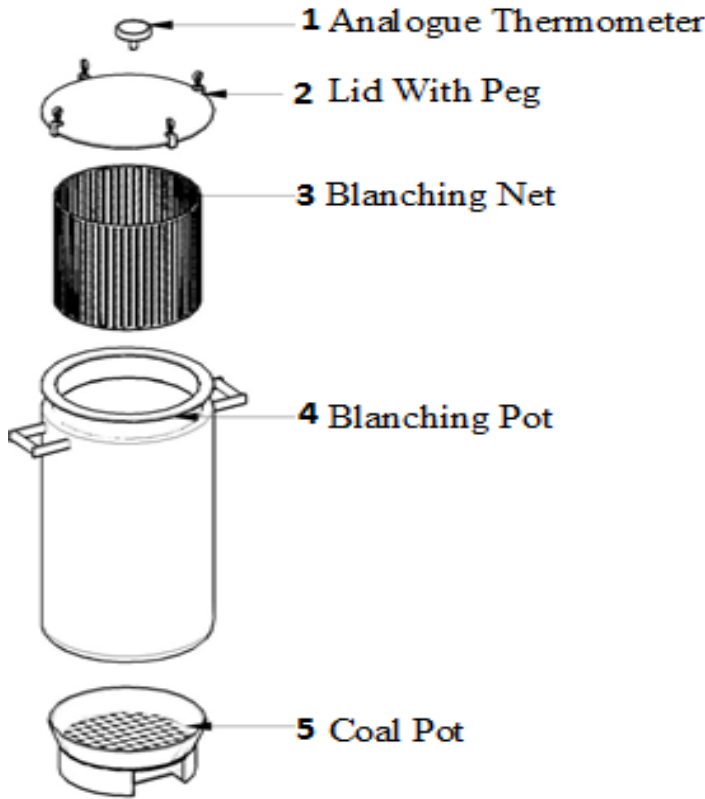

Fig 3b. Exploded View of the Fruit and Vegetable Blancher (Charcoal Source) 
The blancher was plugged to electricity and the temperature regulator will be set to a required blanching temperature otherwise, the coal pot filled with already ignited charcoal could be slotted in if electricity is unavailable at a required blanching time. When the blanching time was over, the blanched tomatoes and pumpkin leaves were then taken to the laboratory to determine if it retains it color and nutritional content. Plates 1 to 6 show the picture of whole tomatoes, sliced tomatoes, sliced tomatoes arranged in blanching net, whole pumpkin, cut pumpkin leaves and the pictorial view of the fruit and vegetable blancher respectively. Also Figure $3 \mathrm{a}$ and $3 \mathrm{~b}$ show the exploded views of the fruit and vegetable blancher with electric Source and charcoal source respectively.

\section{RESULTS AND DISCUSSION}

Table 1 and Table 2 show the data of some nutritional content of raw, water blanched and steam blanched tomatoes and pumpkin leave (Telfairia occidentalis) respectively. Figures 4 and 5 show the graphical illustration of the nutritional contents of raw, steam and water blanched tomatoes and pumpkin leaves respectively. Hot water and steam blanching significantly decrease the ascorbic acid content to
$32.43 \mathrm{mg} / 100 \mathrm{~g}$ and $29.66 \mathrm{mg} / 100 \mathrm{~g}$ respectively for tomatoes and $41.08 \mathrm{mg} / 100 \mathrm{~g}$ and $32.16 \mathrm{mg} / 100 \mathrm{~g}$ respectively for pumpkin leaves. This observation agreed to (Lee et al., 2000) that the main mechanisms of ascorbic acid loss during steam and water blanching could be enzymatic oxidation and thermal degradation, the main mechanism of ascorbic acid losses during hot water blanching is leaching or diffusion from the plant to the blanching water. Vitamin $\mathrm{C}$ is highly water-soluble and sensitive to heat. These properties make it susceptible to processing technologies as well as cooking in the home. Also, the result agrees with the findings of Nkafamiya et al., 2010 who also reported a decrease in the vitamin contents during the blanching of nonconvectional leafy vegetables. According to the Centers for Disease Control and Prevention, good sources of vitamin $\mathrm{C}$ include tomatoes as well as leafy greens. Estimated values revealed significant decrease in vitamin $\mathrm{C}$ content in the blanched fruit sample. This could be due to the fact that vitamin $C$ is by far the least stable nutrient during processing; it is highly sensitive to oxidation and leaches into water during processing (Franke et al., 2004; Patras et al., 2011). The decrease agrees with earlier findings on some Nigerian vegetables that reported $47.5-82.4 \%$ loss in vitamin $\mathrm{C}$ content during blanching (Oboh, 2005).

Table 1. Nutritional contents of tomatoes

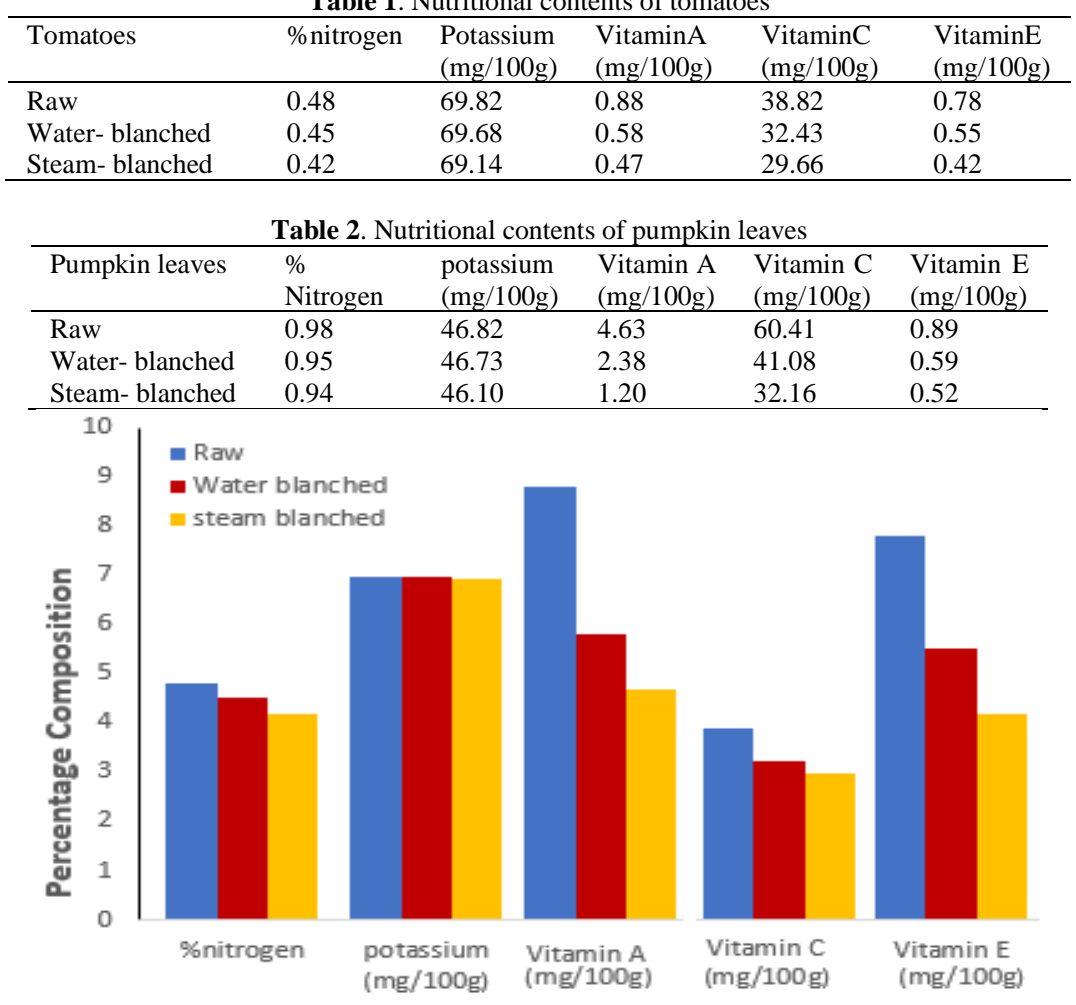

Nutritional Contents

Fig 4: Nutritional content of raw, water blanched and steam blanched tomatoes 


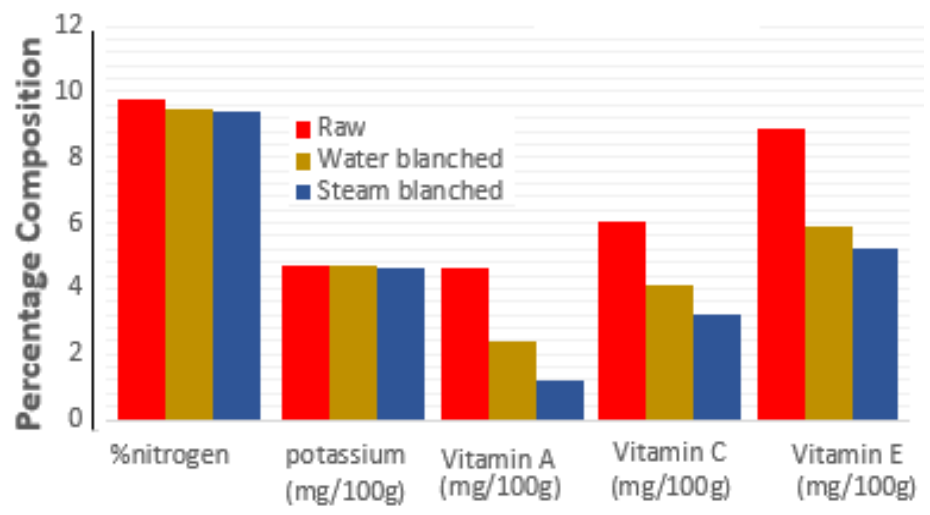

\section{Nutritional Contents}

Fig 5: nutritional content of raw, water blanched and steam blanched pumpkin leave

Figure 4 and 5 shows the effect of blanching (hot water and steam blanching) on the \% nitrogen of fresh tomatoes and pumpkin leave respectively. From the figures, the interpretation is the same as that of the effect it has on ascorbic acid content. Raw tomatoes had a \%nitrogen initial content of 0.48 and that of raw pumpkin leave of 0.98 . The values in both products reduces significantly in both water and steam blanching treatment to 0.45 and 0.42 for tomatoes respectively and 0.95 and 0.94 respectively for pumpkin leave. These findings are in accordance with a report that green leafy vegetables are good sources of dietary minerals (Akindahunsi and Oboh,1999). However, all processing of the leaves caused significant decrease in all the minerals analyzed. These findings agreed with earlier reports by (Akindahunsi and Oboh, 1999) that blanching may cause a significant decrease in the mineral composition of leafy vegetables.

The initial potassium content of tomatoes and pumpkin leaves decreases insignificantly from $69.82 \mathrm{mg} / 100 \mathrm{~g}$ and $46.82 \mathrm{mg} / 100 \mathrm{~g}$ respectively to $69.68 \mathrm{mg} / 100 \mathrm{~g}$ and $46.73 \mathrm{mg} / 100 \mathrm{~g}$ respectively for water blanching and to $69.14 \mathrm{mg} / 100 \mathrm{~g}$ and $46.10 \mathrm{mg} / 100 \mathrm{~g}$ respectively for steam blanching.

The soluble fraction contains $39 \%$ of the total amount of the mineral indicating that part of the mineral is connected to insoluble structures and is not readily accessible in the raw vegetable. Blanching for 1 minute increased the concentration of potassium in the soluble fraction to 54 and $44 \%$ respectively of the total amount of element initially present (NRC, 1989). This result is in agreement with the findings of other researchers (Oboh, 2005; Mepha et al., 2007; Musa and Ogbadoyi, 2012) who reported that various conventional food processing techniques such as blanching and cooking caused significant reductions in mineral contents of vegetables.
For vitamin $\mathrm{A}$, it also follows the same pattern as that of vitamin $\mathrm{C}$. The raw tomatoes had an initial content of $0.88 \mathrm{mg} / 100 \mathrm{~g}$ in which the values reduce to $0.58 \mathrm{mg} / 100 \mathrm{~g}$ for water blanching and $0.47 \mathrm{mg} / 100 \mathrm{~g}$ for steam blanching and also, the pumpkin leave had an initial content of $4.63 \mathrm{mg} / 100 \mathrm{~g}$ and reduces to 2.38 for water blanching and $1.20 \mathrm{mg} / 100 \mathrm{~g}$ for steam blanching. For vitamin E, raw tomatoes had an initial content of $0.78 \mathrm{mg} / 100 \mathrm{~g}$ and reduces significantly to 0.55 for water blanching and $0.42 \mathrm{mg} / 100 \mathrm{~g}$ for steam blanching.

The pumpkin leave with initial content of $0.89 \mathrm{mg} / 100 \mathrm{~g}$ reduces to $0.59 \mathrm{mg} / 100 \mathrm{~g}$ and $0.52 \mathrm{mg} / 100 \mathrm{~g}$ for water and steam blanching respectively. The decrease in both vitamin content as reported by (Wiel and Low, 2014) that thermal blanching has negative effect on both vitamins because they are water soluble nutrients and vitamins act as antioxidants that block harmful chemical reactions caused by oxidation in human body.

The reductions of these vitamins may be attributed to leaching and thermal destruction of these vitamins (Jacob, 1999). This observed decrease may be due to the isomerization and oxidation of $\beta$ carotene which is considered as source of provitamin A (Rodriguez, 2001)

Conclusions: This research focused on the development and performance evaluation of a dual power source fruit and vegetable blancher. The water blanching method gave better results in terms of nutritional compositions of tomatoes and pumpkin leaves when compared with steam blanching method of preservation. Also, due to the fluctuation and irregularity in electricity supply, an alternative source of energy (charcoal) has been adopted in this research making the device to be a dual energy source. 


\section{REFERENCES}

Akindahunsi, AA; Oboh, G (1999). Effect of some postharvest treatments on the bioavailability of Zinc from some selected tropical vegetables. La Rivista Italian a Della Grasse 76, 285-287

Best Available Techniques, (2005). Blanching in food industries. Best available technology in food, drink and milk industries

Fellows, PJ (2006). Food processing technology: Principles and Practice. CRS Press LLC, Boca Raton, USA, pp. 233-240

Franke, AA; Custer, LJ; Arakaki, C; MURPHY, SP (2004). Vitamin C and flavonoid levels of fruits and vegetables consumed in Hawaii. J Food Comp Anal 17:1-35

Jacob, MB (1999). The chemical analysis of food products ( $3^{\text {rd }}$ edn. $)$. S. K. Jain, New Delhi, India, pp. 697-783

Lee, SK; Kader, AA (2000). Preharvest and postharvest factors influencing vitamin $\mathrm{C}$ content of horticulture crops Postharvest Biol.Technol, 20 pp. 207-22

Mepha, HD; Eboh, L; Banigo, DEB (2007). Effects of processing treatments on the nutritive composition and consumer acceptance of some Nigerian edible leafy vegetables. Afr. J. Food Agric. Nutr. Dev., $7(1): 1-18$

Musa, A; Ogbadoyi, EO (2012) Effect of processing methods on some micronutrients, anti-nutrients and toxic substances in Hibiscus sabdariffa. Asian J. Biochem., 7:63-79
Nkafamiya, II; Oseameahon, SA; Modibbo, UU; Haggai, D (2010). Vitamins and effect of blanching on nutritional and antinutritional values of nonconventional leafy vegetables. Afr. J. Food Sci. 4 (6). 335 - 341

National Research Council, (1989). National research council. Recommended dietary allowances. National Academy Press, Washington, D.C. 284 p

Oboh, G (2005). Effect of some post-harvest treatments on the nutritional properties of Cnidoscolusacontifolusleaf. Pak. J. Nutr., 4:226230

Patras, A; Tiwari, BK; Brunton, NP (2011). Influence of blanching and low temperature preservation strategies on antioxidant activity and phytochemical content of carrots, green beans and broccoli. LWT Food Sci.Technol 44: 299-306.

Reyes, DE Corcuera, JI; Cavaleri, RP ; Powers, JR (2004). Encyclopedia of agricultural, food, and biological engineering. Pp.1-5, Marcel Dekker, inc., New york, NY

Rodriguez-Amaya, DB (2001). A guide to carotenoids analysis in foods. ILSI Press. Human nutrition Institute. One Thomas Circle, NW, Washington DC, 20005-5802, 64.

Wiel, S; Low, D (2014). Academy of Nutrition and Dietetics: What Is an Antioxidant? Retrieved from http://www.eatright.org/Public/content.aspx?id=38 13 